\title{
Re-evaluating the Effectiveness of Hydroxychloroquine on Urticaria: A Systematic Review
}

\author{
Immanuel Sani $^{*}$, Muambo Eko², Youssef Chedid ${ }^{3}$, Yaser Hamza ${ }^{4}$, Jubilent \\ Amalendran 5 \\ 1*Leicester Medical School, George Davies Centre, Leicester, United Kingdom \\ 2, 3, 4, 5 King's College London, GKT school of medical education, Guy's Campus, London, United \\ Kingdom
}

\begin{abstract}
Keywords:

Hydroxychloroquine, AntiMalarial, Urticaria, Hives, Wheals

Received

25 September 2020

Received in revised form

15 October 2020

Accepted

21 October 2020

*Correspondence:

immanuel.sani@kcl.ac.uk

Urticaria is a common disease characterised by transient erythematous, oedematous, pruritic wheals in the dermis due to the release of various inflammatory mediators from mast cells. There was previously limited evidence on the effectiveness of hydroxychloroquine (HCQ) in the literature but there is now emerging evidence that warrants further investigation. This review aims to appraise the current literature and propose contemporary evidence-based recommendations for hydroxychloroquine treatment of patients with urticaria by performing a systematic review. The MEDLINE, Embase and Cochrane databases were searched from inception to 12 June 2020 in accordance with the PRISMA guidelines. We also examined the reference lists of the retrieved studies. Texts were reviewed independently by two authors. The risk of bias and quality of the studies was assessed using the Critical Appraisal Skills Programme for systematic reviews. A total of 7 studies were included, involving 211 pooled trial participants. There was moderate-quality evidence from two RCTs that revealed the effectiveness of HCQ in the subjective improvement of urticarial symptoms. Two case reports and one case series also demonstrated the therapeutic benefit of HCQ for urticaria. There was considerable heterogeneity of outcome variables and trial designs which did not permit a metaanalysis of the results. The limited available evidence reveals that HCQ is effective for the resolution of urticaria. Further multi-centred, placebo-controlled, RCTs are required in order to reveal the relative effectiveness of HCQ in comparison to current second-line treatment modalities.
\end{abstract}

Urticaria is a dermatologic condition that quintessentially involves transient erythematous, oedematous, and pruritic wheals. Urticaria is a relatively common condition wherein $8-20 \%$ of the 
population experience the aforementioned symptoms at least once in their lifetime [1]. Urticaria is prevalent between the age of 20 and 40 years, with a tendency to affect women more than men [2]. In $40 \%$ of cases, angioedema is concomitant with urticaria which necessitates emergency treatment if there is potential for airway compromise [3]. Chronic urticaria (CU) is the commonest variant of urticaria, comprising up to $90 \%$ of total cases and is characterised by urticarial symptoms that occur at least twice a week for a duration of $>6$ weeks [4]. Urticaria is a debilitating condition which often induces emotional anguish, reduced social interaction and lethargy within affected individuals [5]. Both the physical and psychological sequelae highlights the significance of managing urticaria adequately to improve the quality of life (QoL) in affected individuals.

The principal cause of urticaria is thought to be due to an autoimmune mechanism which accounts for approximately 50\% of all reported cases [6]. There are however several other aetiological factors that may give rise to urticaria such as respiratory allergens or infections, insect bites, contact urticaria, thyroid disease, psychogenic distress, and certain medications [7]. Interestingly, acetylsalicylic acid and non-steroidal anti-inflammatory agents have been implicated in the instigation of urticaria due to downregulation of the cyclo-oxygenase pathway, which in turn causes increased leukotriene formation [8].

The pathophysiology of urticaria involves secretion of proinflammatory mediators, namely histamine, from mast cells due to binding of type 1 immunoglobulin E ( $\operatorname{IgE}$ ) antibodies to highaffinity Fc receptors on the cell surface membrane. In $\mathrm{CU}$, the foreign antigen binds to the $\mathrm{IgE}$ high-affinity Fc receptor situated on the mast cells and basophils in the dermis. If the immune system encounters the same foreign antigen, the IgE antibodies that are already present on the mast cells and basophils immediately bind to the antigen and induce a prompt allergic reaction, which explains the autoimmune phenomena observed in CU [7].

The hypothesised autoimmune reaction of $\mathrm{CU}$ has led to extensive research into and utilisation of pharmacological agents with immunomodulatory properties. Current first-line treatment is second-generation $\mathrm{H} 1$ antihistamines and subsequent treatment involves the use of cyclosporine, montelukast, or omalizumab [9]. Hydroxychloroquine (HCQ), an anti-malarial drug that produces an anti-inflammatory response in other conditions, is an alternative treatment option.

The literature previously suggested that there was a low level of supporting evidence for HCQ. However, there is now emerging evidence that HCQ is potentially effective for CU and elicits fewer side effects compared to conventional therapies [10]. Therefore, this systematic review aims to critically appraise all available evidence on the effectiveness of HCQ on CU.

\section{Methods}

This systematic review is grounded upon the recommendations of the PRISMA statement for systematic reviews [11].

\section{Search Strategy}

An electronic literature search was conducted on the following databases: PubMed, Medline, and Embase up to 12 June 2020, with no restrictions on the publication language. Only articles published beyond the year 2000 were searched. All articles containing the words "urticaria" in conjunction with the terms "hydroxychloroquine" or "hives" or "wheals" or "anti-malarial" or "Plaquenil" or "hydroxychloroquine sulphate" or "chloroquine" were identified. The reference lists of all provisionally selected articles were reviewed for further identification of potentially relevant studies. The grey literature was also reviewed for additional articles. All identified articles were systematically assessed using the inclusion and exclusion criteria. 


\section{Selection Criteria}

The inclusion and exclusion criteria for study selection are itemised in Table 1. Titles and abstracts of all studies found from the database search were manually screened for compatibility with the inclusion criteria by two review authors. The data was extracted based on the nature of participants' urticaria, type of intervention, comparison or control interventions, relevant outcome variables, and study design. Review articles were excluded from the systematic review to curtail publication bias. Articles with no full-length text available were also excluded.

Table 1

Study Selection Inclusion and Exclusion Criteria

\begin{tabular}{|l|l|l|}
\hline & Inclusion criteria & Exclusion criteria \\
\hline Participants & All variants of urticaria in children and adults & N/A \\
\hline Experimental Intervention & Hydroxychloroquine & Non-hydroxychloroquine treatment \\
\hline Comparison or control intervention & $\begin{array}{l}\text { Second-generation H1 antihistamines, } \\
\text { calcineurin inhibitors, montelukast, } \\
\text { omalizumab, naltrexone, or afamelanotide }\end{array}$ & N/A \\
\hline Primary outcome variable & $\begin{array}{l}\text { Any objective and self-reported urticarial } \\
\text { symptom or quality of life measure }\end{array}$ & N/A \\
\hline Study design & $\begin{array}{l}\text { Randomised clinical trials } \\
\text { Case reports/series, cohort study, case- } \\
\text { control study, or cross-sectional study }\end{array}$ & $\begin{array}{l}\text { Systematic review articles, animal model } \\
\text { studies, or opinion articles }\end{array}$ \\
\hline
\end{tabular}

\section{Data Extraction and Critical Appraisal}

A standardised proforma was used to methodically gather data on the nature of the study design, participant characteristics, type of intervention, control or comparative interventions, primary outcome variables, and follow-up intervals if available. Further relevant data such as the funding source, a potential conflict of interests between authors, and reported risk of bias were also obtained.

The risk of bias $(\mathrm{RoB})$ in each study and quality was evaluated by the Critical Appraisal Skills Programme (CASP) tool for randomised clinical trials (RCTs) [12]. Where there was disagreement in the scoring of a CASP domain for a study between reviewers, this was settled by consultation with a third, independent reviewer. The RoB and subsequent methodological quality of the selected studies was ascertained according to the Cochrane Risk of Bias (CRoB) Tool. The CRoB tool was used to assess bias from the following criteria: random sequence generation, allocation concealment, blinding of participants and personnel, blinding of outcome assessment, incomplete outcome data, selective reporting, and other bias. Each criterion was scored as either 'low', 'high', or 'unclear' RoB for each respective study. The overall RoB in a study was categorised as highquality if at least 6 criteria were scored as 'low' RoB and one criterion was scored as 'unclear' RoB. A study was deemed to be moderate-quality if 2 or fewer criteria were scored as 'high' RoB or if 3 criteria were scored as 'unclear' RoB. A study was deemed to be low-quality if 3 or more criteria were scored as 'high' RoB or if at least 4 criteria possessed 'unclear' RoB [13].

Upon critical appraisal of the selected studies, the degree of agreement between the reviewers was substantial where $\mathrm{k}=0.794$. When required, we contacted the authors of the included studies to obtain additional information.

\section{Results}

A total of 184 articles were obtained from the electronic database search. After application of inclusion and exclusion criteria, the elimination of duplicates, screening titles, abstracts, and full 
texts, 7 studies with a cumulative total of 211 trial participants were included in the present systematic review (Figure1). There were no suitable, non-duplicate studies identified from the reference list of the included studies.
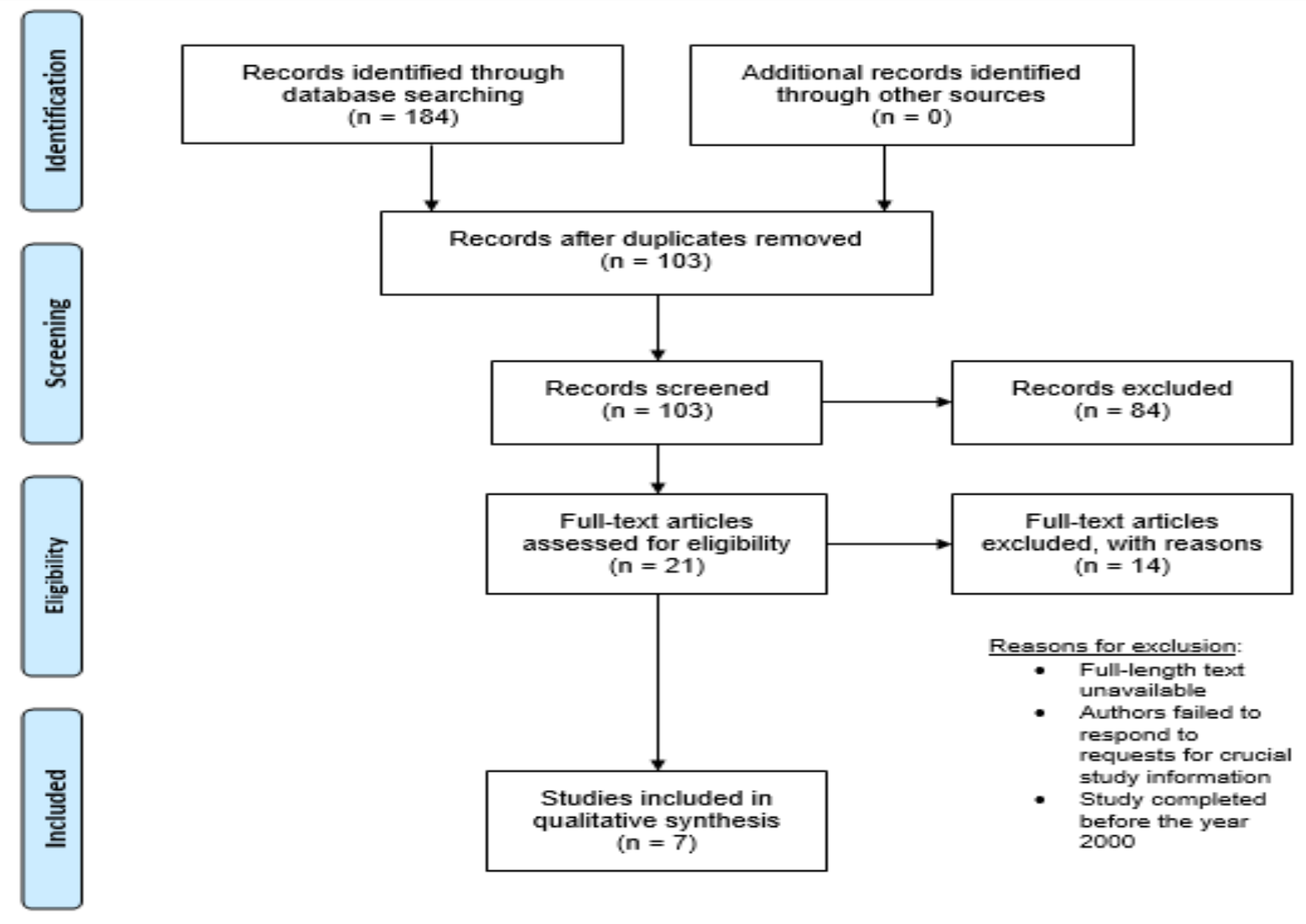

Figure 1. PRISMA Flowchart of Study Selection

\section{Study Characteristics}

Details regarding the key characteristics of the 5 eligible studies are provided in Table 2. A total of 2 RCTs, 2 case reports, 2 retrospective cohort studies, and a single case series were retrieved [1420]. Of the 81 participants who were randomised in the RCTs, 45 (56\%) were assigned to the HCQ treatment group. The pooled mean sample size across the selected studies was 30.1 (range: 1-97). The pooled mean age of participants was 33.5 years (range: 9 months-50 years) and the mean proportion of female individuals was $24.6 \%$. 5 studies did not complete a follow-up assessment. However, 2 studies showed a follow-up period ranging from 4 to 12 weeks.

\section{Critical Appraisal}

The overall quality was moderate for 5 studies (71\%) and low quality for 2 studies (29\%). More specifically, the risk of selection bias (random sequence generation and allocation concealment) was unclear for $43 \%$ of the studies and low for $36 \%$ of the studies. The risk of performance bias (blinding of patients and investigators) and detection bias (blinding of investigators when assessing the outcome) was unclear for $43 \%$ and $71 \%$ of the studies, respectively. Additionally, all of the selected trials presented with low RoB for incomplete outcome data. In summation, we have interpreted the results of the included studies with moderate confidence in the quality of the studies in question. Figure 2 depicts a RoB assessment for each study. 


\section{Hydroxychloroquine}

\section{Mechanism of action}

HCQ exerts its immunomodulatory effects on autoimmune conditions by virtue of alkalinisation of intracellular vacuoles which in turn alters protein degradation by acidic hydrolases in the lysosome, assembly of macromolecules in the endosomes, and post-translation modification of proteins within the Golgi apparatus. It is thought that HCQ interferes with the antigen-processing in macrophages and other analogous lymphocytes. Acidic cytoplasmic compartments are required for the antigenic protein to be digested and for the peptides to assemble with the alpha and beta chains of major histocompatibility complex (MHC) class II proteins. As a consequence of the alkalotic environment, HCQ attenuates the formation of peptide-MHC protein complexes required to activate CD4 and T cells which therefore results in down-regulation of the immune response to auto-antigenic peptides [22].

\section{Efficacy}

In the literature reviewed, 64\% of trial participants received HCQ as a stand-alone intervention whereas the remainder received HCQ in combination with other pharmacological agents which consisted of prednisone, doxepin, cetirizine, montelukast, claratyne, and ranitidine. There was complete abolition of urticarial symptoms in $49 \%$ of participants that received HCQ across all studies. The majority of patients experienced a clinically significant response to HCQ treatment within 8-12 weeks.

\section{Safety and Tolerability}

The current literature shows that HCQ is largely safe and well-tolerated by human subjects. Although, several studies highlighted evidence of adverse reactions to HCQ. A total of 22 separate adverse events were reported by 16-18 individual participants. In the study by Boonpiyathad et al., [15] one participant reported a severe headache during the first week of taking HCQ. Furthermore, 4 participants perceived their skin was darker in complexion. However, none of the subjects complained about ocular deficits and all of the subjects had passed their ophthalmological examination at the end of the study [15]. The risk of HCQ-derived retinopathy is low within the first 5 years of use, but after 5 years of use, the risk rises to approximately 1\% [21]. Ditto et al. [18], reported one female patient had symptoms of flashing lights in her visual field with no visual loss after 3 months of HCQ treatment, so treatment was terminated at the time [18]. Eastman et al. [19] revealed 13 participants experienced minor adverse effects from the medication and discontinued HCQ treatment. The nature of the adverse effects was not disclosed by the authors [19]. Lastly, the study by Pongonis et al. [20], showed that 3 participants discontinued the HCQ treatment one month after commencement due to the formation of a rash and mucosal blistering [20]. Overall, the total incidence rate of adverse events following HCQ treatment for urticaria across the reviewed studies was $10.4 \%$. Whilst the incidence rate is significant, it is difficult to ascertain whether HCQ is truly the contributing factor for the reported adverse reactions as there are several confounding factors wherein some trial participants may have begun a course of non-HCQ treatment before the instigation of the trial and a sufficient wash-out period may not have been implemented by the investigators. Additionally, 23.7\% of all participants received HCQ in combination with other medications and such pharmacodynamic interactions could explain the adverse reactions, rather than HCQ in isolation. Ultimately, the reported adverse events should be interpreted with caution due to the presence of confounding bias. 
Table 2

Characteristics of Selected Studies

\begin{tabular}{|c|c|c|c|c|c|}
\hline $\begin{array}{lr}\begin{array}{l}\text { Author(s), } \\
\text { design, } \\
\text { country }\end{array} & \begin{array}{r}\text { study } \\
\text { date, }\end{array} \\
\end{array}$ & $\begin{array}{l}\text { Participant } \\
\text { characteristics }\end{array}$ & HCQ Intervention & $\begin{array}{l}\text { Comparison/ } \\
\text { Control } \\
\text { intervention }\end{array}$ & $\begin{array}{l}\text { Assessment } \\
\text { interval(s) }\end{array}$ & $\begin{array}{l}\text { Outcome } \\
\text { variable(s) }\end{array}$ \\
\hline $\begin{array}{l}\text { Reeves et al., RCT, } \\
2004 \text { [14] } \\
\text { Australia }\end{array}$ & $\begin{array}{l}\text { Condition: } \\
\text { idiopathic chronic } \\
\text { urticaria } \\
\text { Placebo group: } \mathrm{n}=9 \\
\mathrm{HCQ} \text { treatment } \\
\text { group: } \mathrm{n}=9 \\
\text { Proportion of } \\
\text { females in study = } \\
20 \% \\
\text { Mean age of total } \\
\text { participants }=38.20 \text {, } \\
\text { SD N/D }\end{array}$ & $\begin{array}{ll}\text { HCQ treatment } \\
\text { group dosage: } \\
\text { 1.Ranitidine } & \\
\text { mg BD } & 150 \\
\text { 2.Claratyne } & -20 \\
\text { mg/day } & \\
\text { 3.Cetirizine } & -20 \\
\text { mg/day } & \\
\text { 4.Doxepin- } & 20 \\
\text { mg/day } & \\
\begin{array}{l}\text { 5.Prednisone } \\
\text { mg/day }\end{array} & 20 \\
\text { 6. HCQ - N/D } & \end{array}$ & 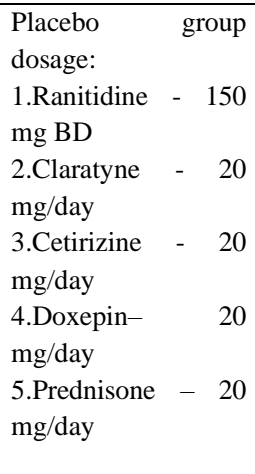 & $\begin{array}{lr}\text { Measurements } & \text { at } \\
\text { baseline and } & 12 \\
\text { weeks }\end{array}$ & $\begin{array}{l}\text { 1.GSSS } \\
\text { 2.US } \\
\text { 3.SF-12 } \\
\text { 4.LAMY-7 } \\
\text { 5.Medication score }\end{array}$ \\
\hline $\begin{array}{l}\text { Boonpiyathad et al., } \\
\text { RCT, } 2017 \text { [15] } \\
\text { Thailand }\end{array}$ & $\begin{array}{l}\text { Condition: } \\
\text { antihistamine- } \\
\text { refractory chronic } \\
\text { spontaneous } \\
\text { urticaria } \\
\text { 1. Placebo group: } \mathrm{n} \\
=27 \\
2 . \mathrm{HCQ} \text { treatment } \\
\text { group: } \mathrm{n}=28 \\
\text { Proportion of female } \\
\text { participants in study } \\
=85.4 \% \\
\text { Mean age of total } \\
\text { participants = } 33.48 \\
\pm 12.01\end{array}$ & $\begin{array}{l}\text { HCQ treatment } \\
\text { group dosage: } 400 \\
\text { mg/day for } 12 \text { weeks }\end{array}$ & $\begin{array}{l}\text { Placebo group } \\
\text { dosage: } 4 \text { tablets of } \\
\text { H1-antihistaminee } \\
\text { drug for } 12 \text { weeks }\end{array}$ & 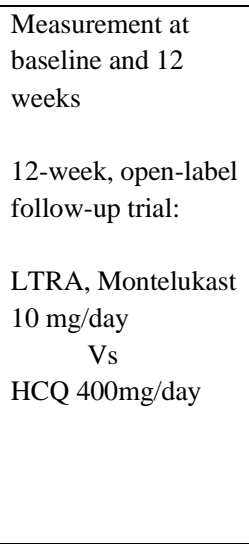 & $\begin{array}{l}\text { 1.US } \\
\text { 2.DLQI }\end{array}$ \\
\hline $\begin{array}{l}\text { Iweala et al., Case } \\
\text { report, } 2018 \text { [16] } \\
\text { USA }\end{array}$ & $\begin{array}{l}\text { Condition: chronic } \\
\text { urticaria } \\
\text { HCQ treatment } \\
\text { group: } \mathrm{n}=1 \\
\text { Male patient } \\
\text { Age of patient: 9 } \\
\text { months }\end{array}$ & $\begin{array}{l}\text { HCQ treatment } \\
\text { group dosage: } \\
\text { 1.Cetirizine } 4 \mathrm{mg} \mathrm{BD} \\
\text { 2. Ranitidine } 37.5 \\
\mathrm{mg} \mathrm{BD} \\
\text { 3.Montelukast } \\
\mathrm{mg} / \text { day } \\
\text { 4.Prednisolone } 0.65 \\
\mathrm{mg} / \mathrm{kg} \text { per day } \\
\text { 5.HCQ } 2 \mathrm{mg} / \mathrm{kg} \text { per } \\
\text { day. Target dose of } 4 \\
\mathrm{mg} / \mathrm{kg} \text { per day over a } \\
\text { 2-week period }\end{array}$ & N/A & $\begin{array}{l}\text { Measurements at } \\
\text { baseline and monthly } \\
\text { assessments from } \\
\text { month 10-24. }\end{array}$ & $\begin{array}{l}\text { 1.Symptom } \\
\text { observation }\end{array}$ \\
\hline $\begin{array}{l}\text { Merhi et al., Case } \\
\text { report, } 2017 \text { [17] } \\
\text { Lebanon }\end{array}$ & $\begin{array}{l}\text { Condition: cold } \\
\text { urticaria with } \\
\text { angioedema } \\
\text { HCQ treatment } \\
\text { group: } \mathrm{n}=1 \\
\text { Female patient } \\
\begin{array}{l}\text { Age of patient: } 50 \\
\text { years }\end{array}\end{array}$ & $\begin{array}{l}\mathrm{HCQ} \quad \text { treatment } \\
\text { dosage: } 200 \mathrm{mg} \mathrm{BD}\end{array}$ & N/A & $\begin{array}{l}\text { Measurement at } \\
\text { weeks } 4,8 \text { and } 12 .\end{array}$ & $\begin{array}{l}\text { 1.Cold stimulation } \\
\text { test } \\
\text { 2.Symptom } \\
\text { observation }\end{array}$ \\
\hline $\begin{array}{l}\text { Ditto et al., } 2007 \\
\text { [18], Case series, } \\
\text { USA }\end{array}$ & 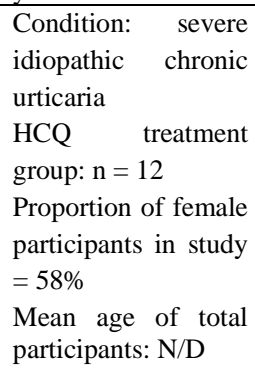 & $\begin{array}{l}\text { HCQ treatment } \\
\text { group dosage: } \\
\text { 1.HCQ } 200 \mathrm{mg} \mathrm{BD} \\
\text { 2.Prednisone } \\
\text { dosage N/D } \\
\text { 3.Doxepin - dosage } \\
\text { N/D }\end{array}$ & N/A & $\begin{array}{lr}\text { Measurement at } \\
\text { baseline, } 3 \text { months, } 9 \\
\text { months, and } 12 \\
\text { months. }\end{array}$ & $\begin{array}{l}\text { 1.Symptom } \\
\text { observation } \\
\text { 2. Ophthalmology } \\
\text { examination }\end{array}$ \\
\hline
\end{tabular}




\begin{tabular}{|c|c|c|c|c|c|}
\hline $\begin{array}{l}\text { Eastman et al., } \\
\text { retrospective cohort } \\
\text { study, 2014 [19] } \\
\text { USA }\end{array}$ & $\begin{array}{l}\text { Condition: chronic } \\
\text { urticaria } \\
\text { HCQ treatment } \\
\text { group: } \mathrm{n}=97 \\
\text { Proportion of female } \\
\text { participants in study } \\
=\mathrm{N} / \mathrm{D} \\
\text { Mean age of total } \\
\text { participants: N/D }\end{array}$ & $\begin{array}{l}\mathrm{HCQ} \text { treatment } \\
\text { dosage: N/D }\end{array}$ & N/A & $\begin{array}{l}\text { Single patient chart } \\
\text { review assessment }\end{array}$ & $\begin{array}{l}\text { 1.Symptom } \\
\text { observation }\end{array}$ \\
\hline $\begin{array}{l}\text { Pongonis et al., } \\
\text { retrospective cohort } \\
\text { study, 2012 [20] } \\
\text { USA }\end{array}$ & $\begin{array}{l}\text { Condition: } \\
\text { antihistamine- } \\
\text { refractory chronic } \\
\text { urticaria } \\
\text { HCQ treatment } \\
\text { group: } \mathrm{n}=19 \\
\text { Proportion of female } \\
\text { participants in study } \\
=\mathrm{N} / \mathrm{D} \\
\text { Mean age of total } \\
\text { participants: N/D }\end{array}$ & $\begin{array}{l}\text { HCQ treatment } \\
\text { group dosage: } \\
\text { 1.HCQ - dosage N/D } \\
\text { 2.Oral corticosteroid } \\
\text { - dosage N/D }\end{array}$ & N/A & $\begin{array}{l}\text { Single patient chart } \\
\text { review assessment }\end{array}$ & $\begin{array}{l}\text { 1.Patient-reported } \\
\text { symptom change }\end{array}$ \\
\hline
\end{tabular}

Notes: BD - Bi-daily, DLQI - Dermatology life quality index GSSS - Global symptom severity score, HCQ - Hydroxychloroquine, LAMY-7 Lamy 'smiley faces' quality of life index, LTRA - Leukotriene receptor antagonists, N/D - Not detected, RCT - Randomised clinical trial, SF Short form 12 quality of life index, SD - Standard deviation, N/A - Not applicable, US - Urticarial score

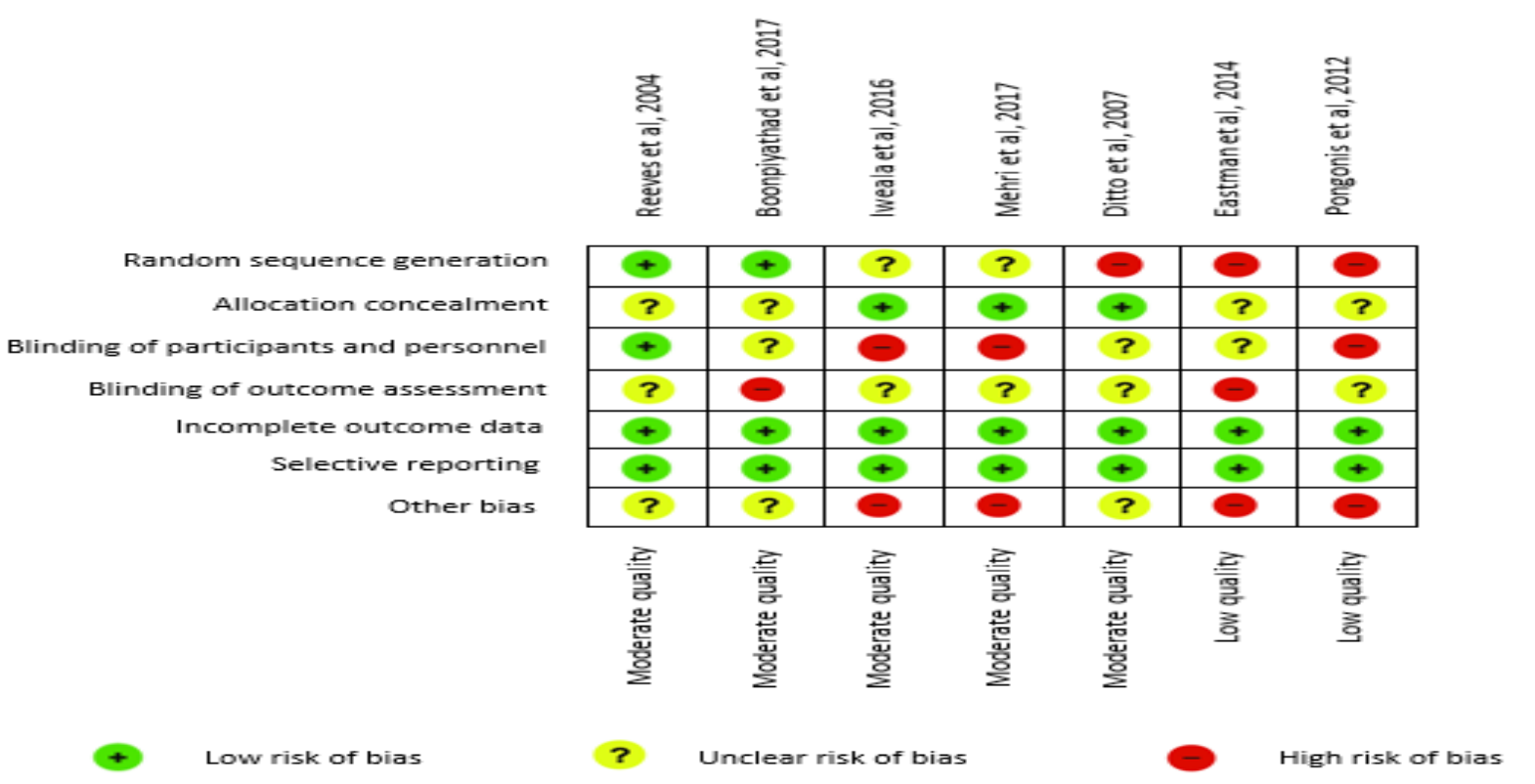

Figure 2. Methodological quality appraisal of selected studies and associated risk of bias

\section{Discussion}

Urticaria is a markedly debilitating condition, especially in chronic cases, however, utilisation of HCQ appears to be a promising second-line treatment to resolve recalcitrant cases of urticaria. In the present systematic review, we merged data from 7 studies involving 211 participants. These studies generally adopted a small sample size, with the largest study consisting of 97 participants. Based on RCTs that possessed moderate and low risk of bias, we discovered moderate to highquality evidence that HCQ has a significant effect upon the improvement of urticarial symptoms and QoL in patients predominantly with CU. All 7 studies in this review concluded that HCQ was indeed effective for urticarial symptom attenuation.

Firstly, the RCT by Reeves et al. [14] demonstrated a statistically significant improvement in the HCQ-treatment group's QoL as assessed by the GSSS and the LAMY-7 at 12 weeks. The mean 
change in the HCQ treatment group's QoL was 0.4 [ -7.4 to 6.6] (95\% CI). The treatment effect on medication requirements and US was insignificant, although there was a noticeable improvement in the HCQ treatment group, which marginally failed to reach statistical significance $(\mathrm{P}=0.05-$ 0.10 ) and therefore raises the possibility of a true treatment effect. Despite these positive findings, the observed treatment effect on global, non-specific symptoms may indicate a Type I (false positive) error owing to the small study sample size and limited the study's power to detect a significant change or a lack thereof in other explicit measures of symptomology such as US.

The results in the study by Reeves et al. [14] were corroborated by Boonpiyathad et al. [15] which revealed that after 12 weeks, the US was significantly improved in the HCQ treatment group $(\mathrm{p}=0.0001)$. The patients in this trial also experienced superior improvements in DLQI scores following HCQ treatment compared to the placebo group $(\mathrm{p}=0.004)$. A striking feature of this study was in the outcome of the follow-up study whereby 24 and 19 participants received HCQ and LTRA (montelukast), respectively in an open-label comparison study. By the end of the follow-up study, there was no significant variance in the mean US scores (38.54 \pm 12.30 and $34.77 \pm 10.90)$ and DLQI scores $(8.68 \pm 3.51$ and $7.83 \pm 2.72)$ between the HCQ and LTRA groups. The HCQ treatment group did however display a greater rate of remission at $22.72 \%$ relative to the $5.55 \%$ of the LTRA treatment group. The results of the follow-up comparison study imply that HCQ may confer a superior therapeutic effect compared to LTRAs and as such, HCQ should be considered to supersede montelukast in the current treatment algorithm for urticaria as there may be a reduction in healthcare consumption from patients for urticaria treatment if symptoms are better-controlled through the use of HCQ.

Furthermore, both case reports by Iweala [16] and Merhi et al. [17] as well as the case series by Eastman et al. [19], all provide further low to moderate quality supporting evidence for the effectiveness of HCQ. Iweala et al. [16] reported that an infant's urticaria was resolved after one month of HCQ treatment. Additionally, Eastman et al. showed that $73.2 \%$ of patients in the study attained complete or partial response to $\mathrm{HCQ}$, with a 2.3 month mean response time to treatment. The study by Merhi et al. [17] was unique in that the investigators demonstrated that $200 \mathrm{mg}$ of daily HCQ treatment resulted in resolution of the cold urticaria - a sub-classification of urticaria in which wheals appear on the skin soon after exposure to a cold stimulus, after 5 weeks. The results of this study are of great interest as it highlights the versatility of HCQ in the treatment of analogous urticarial pathologies and therefore warrants further investigation. It is important to note that all three studies did not use a control group and we cannot therefore definitively infer that HCQ was the causative factor for the observed treatment effect. Although, the findings from the case series by Eastman et al. [19] substantiates the notion of a causal relationship between HCQ and urticarial symptom resolution to a large extent.

Lastly, the retrospective cohort study by Pongonis et al. [20] revealed that $63 \%$ of patients reported improved control of urticaria with the use of HCQ. Within the group of patients with improved symptoms, 50\% also reported complete resolution of symptoms. A possible explanation for the absence of symptomatic improvement in the remaining $37 \%$ of patients in the study is that all patients were unresponsive to antihistamine treatment and the severity of their urticaria may have necessitated more advanced therapy perhaps in the form of omalizumab. Conversely, the authors did not mention the implementation of a wash-out period and the symptomatic improvement reported by the majority of patients may have been derived from the latent treatment effect of the previous antihistamine treatment. Due to the nature of the study, it is difficult to establish a true causal relationship. 
We acknowledge several limitations in this systematic review. The case reports and case series with small sample numbers account for the majority of the studies included in the review, and thus the methodological quality of the reviewed data is questionable as per the CRoB tool. More specifically, there was a dearth of high-quality RCTs in the literature search. The inclusion of trials whereby a placebo control group was absent may result in either underestimation or overestimation of the true treatment effect of HCQ in urticaria. However, all studies in the review described favourable results, with a reduction or absence of wheals typically observed within 8-12 weeks. Additionally, the considerable heterogeneity in study design and utilisation of subjective, qualitative outcome variables did not permit a meta-analysis, and therefore the clinical significance of HCQ could not be deduced.

To our knowledge, this is the first systematic review to specifically collate and appraise the literature on HCQ in urticaria. We hope that this review will highlight the need for further research to reform the current treatment for this relatively common and unpleasant condition. We make the following recommendations for future research on this topic: 1) Use of a randomised multi-centre, placebo-controlled trial design with an appropriate sample size to facilitate minimally biased measurements on the effectiveness, tolerability, and duration of the HCQ treatment effect ;2) Consistent and comprehensive reporting of adverse events ;3) compare HCQ to current second-line medications to ascertain the relative effectiveness of HCQ and inform current urticaria treatment guidelines ;4) Focus primarily on recruiting individuals with chronic urticaria as epidemiological data shows that this is the most common variant of urticaria.

\section{Conclusion}

The literature presents low to moderate quality evidence which supports the use of HCQ to resolve urticaria. The findings of this systematic review suggest that HCQ may be a feasible second-line treatment for urticaria and circumvent the side-effects associated with long-term oral corticosteroid use. Further high-quality trials are warranted to compare the effectiveness of HCQ to current second-line treatment modalities for urticaria. Ultimately, the full patient context must be considered prior to the prescription of HCQ depending on the patient's preference, previous drug and medical history, and severity of symptoms.

\section{Acknowledgements}

We thank the authors of the selected studies who provided additional information upon request for this systematic review.

\section{Declaration of Conflicting Interests}

The authors do not have any conflicting interests to declare.

\section{Funding}

The authors did not receive any financial support for the research, authorship, and/or publication of this article. 


\section{References}

[1] Darlenski R, Kazandjieva J, Zuberbier T, Tsankov N. Chronic urticaria as a systemic disease. Clinics in Dermatology. 2014 May 1;32(3):420-3.

[2] Deacock S. An approach to the patient with urticaria. Clinical \& Experimental Immunology. 2008;153(2):151-161.

[3] Kaplan AP. Chronic urticaria and angioedema. New England Journal of Medicine. 2002 Jan 17;346(3):175-9.

[4] Zuberbier T, Henz BM, Greaves MW, Juhlin L, Kobza-Black A, Maurer D, Stingl G. Definition, classification, and routine diagnosis of urticaria: a consensus report. Journal of Investigative Dermatology Symposium Proceedings. 2001;6(2):123127.

[5] O'donnell BF, Lawlor F, Simpson J, Morgan M, Greaves MW. The impact of chronic urticaria on the quality of life. British Journal of Dermatology. 1997 Feb;136(2):197-201.

[6] Kaplan AP. Chronic urticaria: pathogenesis and treatment. Journal of Allergy and Clinical Immunology. 2004 Sep $1 ; 114(3): 465-74$.

[7] Kayiran MA, Akdeniz N. Diagnosis and treatment of urticaria in primary care. Northern clinics of Istanbul. 2019;6(1):93.

[8] Palikhe NS, Sin HJ, Kim SH, Sin HJ, Hwang EK, Ye YM, Park HS. Genetic variability of prostaglandin E2 receptor subtype EP4 gene in aspirin-intolerant chronic urticaria. Journal of Human Genetics. 2012 Aug;57(8):494-9.

[9] Zuberbier T, Aberer W, Asero R, Bindslev-Jensen C, Brzoza Z, Canonica GW, Church MK, Ensina LF, Giménez-Arnau A, Godse K, Gonçalo M. The EAACI/GA 2 LEN/EDF/WAO Guideline for the definition, classification, diagnosis, and management of urticaria: the 2013 revision and update. Allergy. 2014 Jul;69(7):868-87.

[10] Vestergaard C, Deleuran M. Chronic spontaneous urticaria: latest developments in aetiology, diagnosis, and therapy. Therapeutic Advances in Chronic Disease. 2015;6(6):304-313.

[11] Liberati A, Altman DG, Tetzlaff J, Mulrow C, Gøtzsche PC, Ioannidis JP, Clarke M, Devereaux PJ, Kleijnen J, Moher D. The PRISMA statement for reporting systematic reviews and meta-analyses of studies that evaluate health care interventions: explanation and elaboration. Journal of Clinical Epidemiology. 2009 Oct 1;62(10):e1-34.

[12] CASP website.URL: https://casp-uk.net/wp-content/uploads/2018/01/CASP-Randomised-Controlled-Trial-Checklist2018.pdf. Published 2018. Accessed on July 22020.

[13] Higgins JP, Altman DG, Gøtzsche PC, Jüni P, Moher D, Oxman AD, Savović J, Schulz KF, Weeks L, Sterne JA. The Cochrane Collaboration's tool for assessing risk of bias in randomised trials. Bmj. 2011 Oct 18;343:d5928.

[14] Reeves GE, Boyle MJ, Bonfield J, Dobson P, Loewenthal M. Impact of hydroxychloroquine therapy on chronic urticaria: chronic autoimmune urticaria study and evaluation. Internal Medicine Journal. 2004 Apr;34(4):182-6.

[15] Boonpiyathad T, Sangasapaviliya A. Hydroxychloroquine in the treatment of antihistamine refractory chronic spontaneous urticaria, randomized single-blinded placebo-controlled trial and an open label comparison study. European Annals of Allergy and Clinical Immunology. 2017;49(05):220.

[16] Iweala OI, Copenhaver C, Wu EY, Moran TP. Hydroxychloroquine as a steroid-sparing agent in an infant with chronic urticaria. Annals of Allergy, Asthma and Immunology. 2018 Jan 1;120(1):102-4.

[17] Merhi R, Ayoub N, Hajj C, Mrad M. Hydroxychloroquine, cold urticaria, and the ice bucket challenge: A case report. Journal of Dermatology and Dermatologic Surgery. 2017 Jul 1;21(2):98-9.

[18] Ditto A. Hydroxychloroquine in the treatment of 12 patients with severe chronic idiopathic urticaria; A case series. Journal of Allergy and Clinical Immunology. 2007;119(1):S199.

[18] Ditto A. Hydroxychloroquine in the treatment of 12 patients with severe chronic idiopathic urticaria; A case series. Journal of Allergy and Clinical Immunology. 2007;119(1):S199.

[19] Eastman J, Wilde N, Jerath M. Outcomes of chronic urticaria patients treated with Hydroxychloroquine. Journal of Allergy and Clinical Immunology. 2014;133(2):AB119.

[20] Pongonis R, Fahrenholz J. Efficacy of Hydroxychloroquine in the treatment of 19 patients with antihistamine-refractory chronic urticaria. Journal of Allergy and Clinical Immunology. 2012;129(2):AB2. 